\title{
CARACTERIZAÇÃO DAS CONDIÇÕES DE MANUTENÇÃO E DOS USOS DA ZONA COSTEIRA DO MUNICÍPIO DE SÃO LUÍS (MA): A EDUCAÇÃO AMBIENTAL COMO ALTERNATIVA DE AMENIZAÇÃO DE IMPACTOS
}

\author{
Naara Suzany da Silva Reis ${ }^{1}$ \\ Paula Verônica Campos Jorge Santos ${ }^{2}$
}

Resumo: O crescimento das cidades reforça problemas de ordem ambiental, e quando em áreas costeiras tendem a serem potencializados por conta da sensibilidade dos ecossistemas ali presentes. No Estado do Maranhão, a zona costeira possui 640 $\mathrm{km}$ de extensão, correspondendo a segunda maior região costeira do Brasil, na qual se encontra características geoambientais diversificadas, tendo grande potencial pesqueiro, turístico, portuário e um rico ecossistema. Este trabalho visou caracterizar as condições de usos e manutenção da zona costeira do Município de São Luís, e avaliar quais as aplicações possíveis da Educação Ambiental como ferramenta de resolução de problemas caraterizados.

Palavras-chave: Crescimento Populacional; Zona Costeira; Resíduos Sólidos; Educação Ambiental.

Abstract: The growth of cities reinforces environmental problems, and when in coastal areas they tend to be enhanced due to the sensitivity of the ecosystems present there. In the State of Maranhão, the coastal zone is $640 \mathrm{~km}$ long, corresponding to the second largest coastal region in Brazil, in which there are diversified geoenvironmental characteristics, with great fishing, touristic, port and rich ecosystem. This work aimed to characterize the conditions of uses and maintenance of the coastal area of the Municipality of São Luís, and to evaluate which are the possible applications of Environmental Education as a tool for solving characterized problems.

Keywords: Population Growth; Coastal Zone; Solid Waste; Environmental Education.

${ }^{1}$ Engenheira Ambiental. E-mail: naarasuzanyreis@gmail.com

2 Doutora em Biodiversidade e Biotecnologia. E-mail: veve.unifap@gmail.com.

Revbea, São Paulo, V. 15, № 5: 333-344, 2020.

revista brasileira educação ambiental 


\section{Introdução}

A região costeira, área de interface entre ar, mar e terra, é destaca por Gruber, Barboza e Nicolodi (2003) como a região sobre maior estresse ambiental a nível mundial, isso porque está submetida a fortes pressões por intensas e diversificadas forma de uso do solo. Estimam que nesse século, $80 \%$ das atividades humanas, se concentrarão nessa zona. Dentre essas atividades destacam-se processos acelerados de intensa urbanização, atividade portuária, industrial relevantes e exploração turística.

Essa região está submetida a fortes pressões pelas formas diversificadas de uso do solo, o que a pequeno, médio e longo prazo pode convergir para inúmeros impactos, com destaque especial para os processos oriundos das diversas formas de apropriação histórica por ocupações desordenadas, e, mesmo daquelas que são fruto do processo de planejamento, mas, que negligenciam à proteção necessária ao funcionamento dos ecossistemas sensíveis presentes nessa região.

$\mathrm{O}$ crescimento das cidades reforça problemas de ordem ambiental, e quando em áreas costeiras tendem a serem potencializados por conta da sensibilidade dos ecossistemas ali presentes. As agressões ao meio ambiente ocorrem devido a uma soma de fatores, ligados basicamente ao uso e ocupação informal do solo, ao crescimento da malha urbana sem o acompanhamento adequado de recursos de infraestrutura e a expansão imobiliária. Assim, áreas inadequadas, como APP's, são ocupadas pela população, ocasionando o comprometimento dos recursos ambientais, com prejuízo para a sociedade como um todo (CORREIA, 2006).

Andrade (2019) avalia que no Brasil, as pressões socioeconômicas na zona costeira vêm desencadeando, ao longo do tempo, um processo acelerado de urbanização não planejada e intensa degradação dos recursos naturais, os quais são uma ameaça à sustentabilidade econômica e à qualidade ambiental e de vida das populações humanas.

No Estado do Maranhão, a zona costeira possui $640 \mathrm{~km}$ de extensão, correspondendo a segunda maior região costeira do Brasil, na qual se encontra características geoambientais diversificadas, tendo grande potencial pesqueiro, turístico, portuário e um rico ecossistema. Silva e Lima (2013) diagnosticam que no município de São Luís, capital do Estado, a ocupação da zona costeira ocorreu em virtude do crescimento populacional da cidade e que em função desse processo de ocupação foram desenvolvidos projetos visando à urbanização e aproveitamento sócio espacial da área, que passou por um processo de especulação imobiliária e projetos voltados para a indústria do turismo, entretanto, esses investimentos parecem estar apresentando sérios problemas socioambientais.

Diante desse cenário, este trabalho buscou caracterizar as condições de Usos e manutenção da zona costeira do Município de São Luís, e avaliar quais as aplicações possíveis da Educação Ambiental como ferramenta de resolução de problemas caraterizados. 


\section{Materiais e Métodos}

\section{Caracterização da área de estudo}

A área em estudo é a região de praias do município de São Luís, composta pelo espigão costeiro, localizado na praia da ponta da areia, seguido da praia de São Marcos, Praia do Calhau, Praia do Caolho e Praia do Olho D’Água, (BORGES et al. 2011), conforme Figura 1.

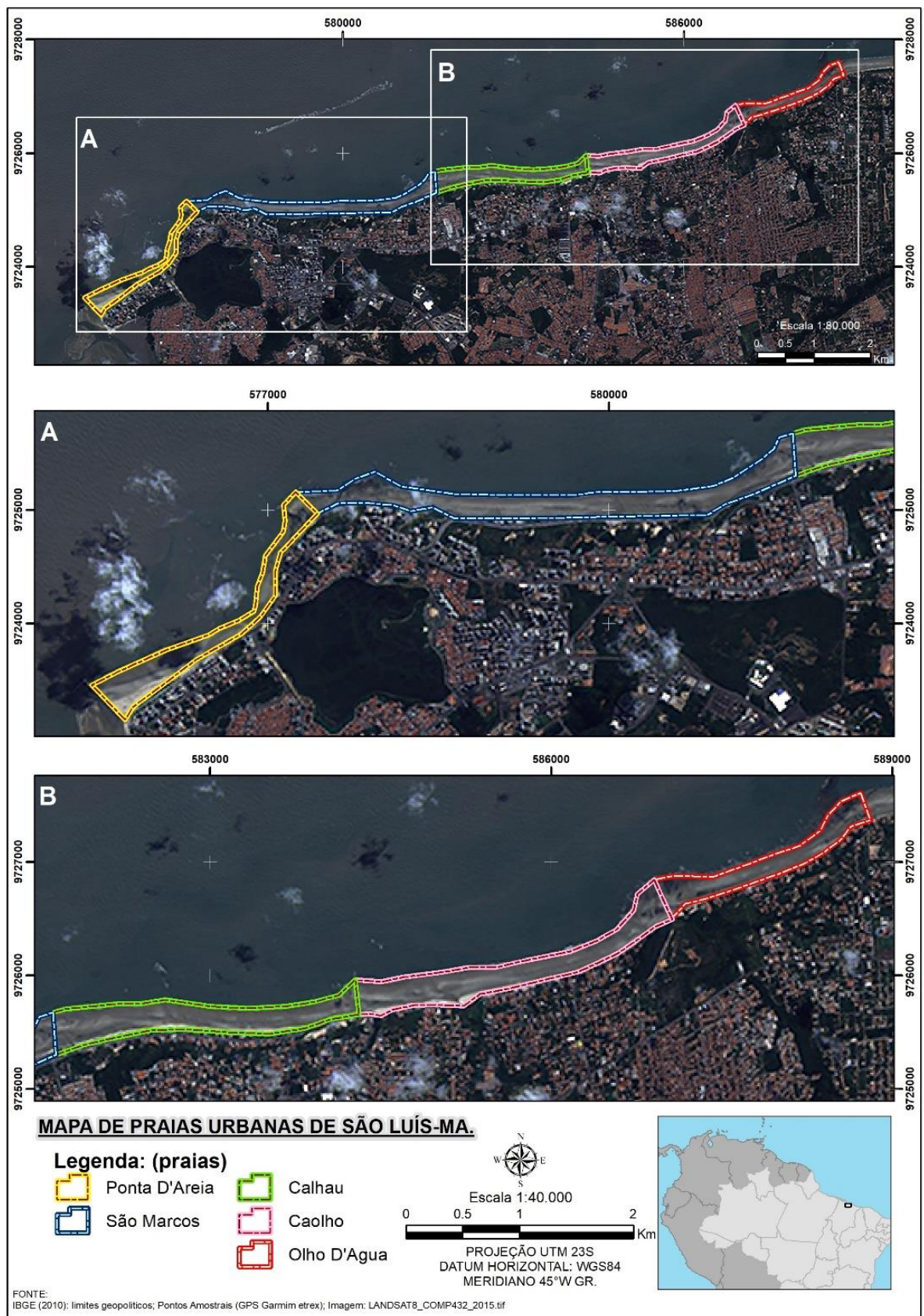

Figura 1: Localização da área de estudo, composta pelas praias da região costeira do município de São Luís (MA). Fonte: Autor. 
O conjunto de praias em estudo é bastante frequentado para 0 desenvolvimento de atividade de turismo, lazer e prática de esportes, o que se não for devidamente gerido pode configurar impactos locais relevantes, tanto de ordem natural quanto antrópica.

Foi utilizada a pesquisa do tipo exploratória que busca proporcionar maior familiaridade com o objeto de estudo (RIBEIRO, et al., 2019). Assim como, pesquisa qualitativa, onde segundo Zanelli (2002), sua utilização é mais indicada quando: a) o objetivo é estudar casos particulares, mais do que abarcar populações extensas; b) deseja-se o entendimento da experiência subjetiva em vez do teste de hipóteses; c) busca-se a análise interpretativa em lugar da manipulação estatística dos fatos; e d) pretende-se tomar os dados na forma de palavras e não de números.

O estudo de caso envolve o estudo profundo de um ou poucos objetos de maneira que se permita o seu amplo e detalhado conhecimento (GIL, 2007). Descrever e caracterizar estudos de caso não é uma tarefa fácil, pois eles são usados de diferentes formas, com abordagens quantitativas e qualitativas, destaca-se ainda o papel relevante do investigador que deverá ter cuidado com as generalizações e buscar sempre o rigor científico no tratamento da questão (VENTURA, 2007).

Dessa forma, para alcançar o objetivo da pesquisa foi realização visita in loco nas praias do município de São Luís. Na ocasião foram feitas observações diretas, anotações em diário de campo e registros fotográficos para a materialização dos fatos.

\section{Resultados e Discussão}

No dia 13 de setembro de 2019 foi realizada visita in loco, na qual foi percorrida a extensão aproximada de $16 \mathrm{~km}$, para a caracterização das condições de manutenção da área (Figura 2).

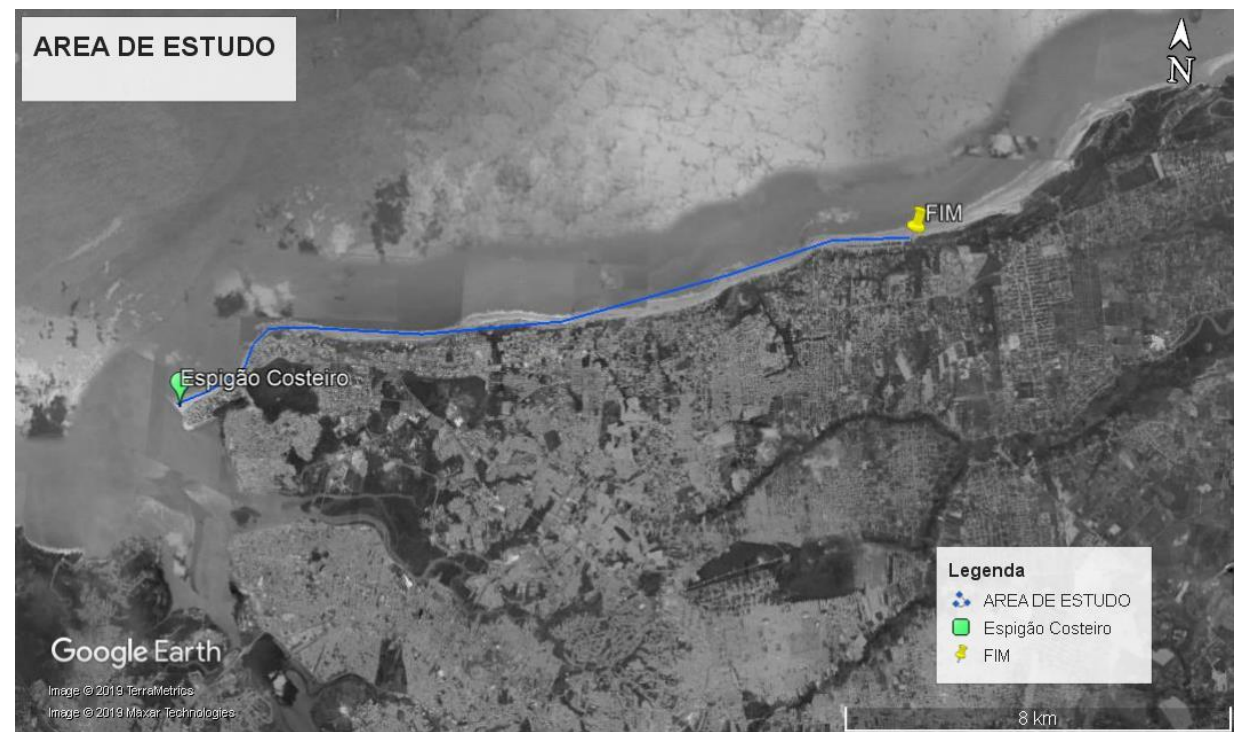


Cabe destacar que ao longo dos $16 \mathrm{~km}$ não foi possível acessar alguns trechos das praias, pois por ocasião da maré alta não era possível o acesso. Os impactos observados foram classificados em impactos de ordem antrópica e de ordem natural, conforme observado na macro classificação abaixo (Quadro 1).

Quadro 1: Classificação da tipologia de Impactos observados no local.

\begin{tabular}{|c|c|}
\hline \multicolumn{2}{|c|}{ IMPACTOS AMBIENTAIS } \\
\hline ANTRÓPICO & NATURAL \\
\hline Descarte irregular de resíduos sólidos & Corrosão de estruturas metálicas \\
\hline Lançamento in natura de resíduos líquidos & $\begin{array}{l}\text { Rebaixamento de nível de estruturas de } \\
\text { construção civil causado pela hidrodinâmica }\end{array}$ \\
\hline $\begin{array}{l}\text { Falta de manutenção de estruturas de uso } \\
\text { comum }\end{array}$ & Engordamento de praia \\
\hline Falta de manutenção de estruturas de suporte & $\begin{array}{l}\text { Movimentação de areia para a via de acesso } \\
\text { urbanizada }\end{array}$ \\
\hline Ocupações humanas & Ruptura de estruturas de acesso da Avenida \\
\hline $\begin{array}{l}\text { Estabelecimentos comerciais regulares } \mathrm{e} \\
\text { irregulares }\end{array}$ & \\
\hline
\end{tabular}

Dentre os impactos antrópicos foi observado que o descarte irregular de resíduos sólidos foi registrado ao longo de toda a extensão percorrida, semdo o impacto mais comum em toda a extensão territorial percorrida (Figura 3 ).
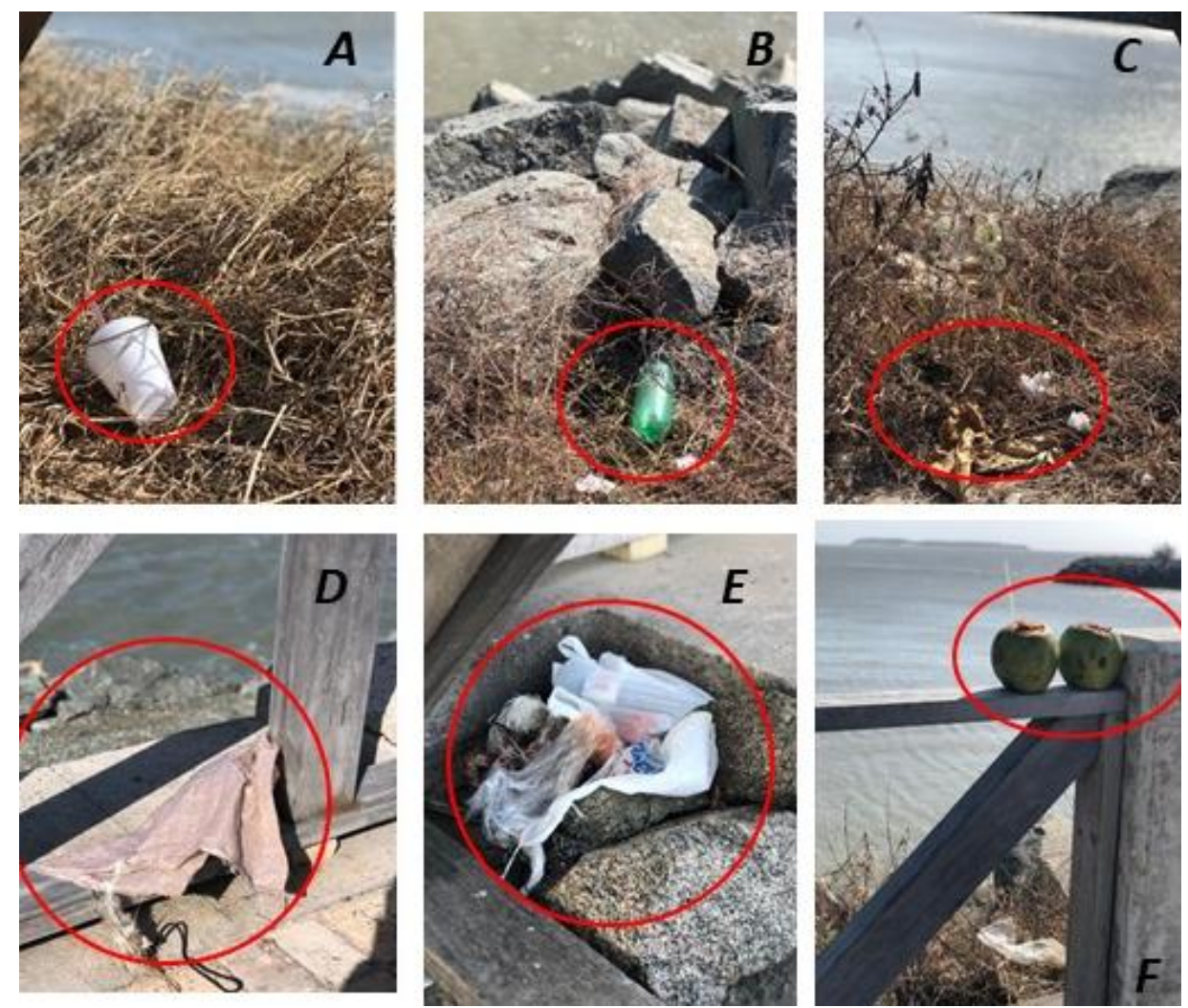

Figura 3: Impactos registrados na Zona de Costa das praias do município de São Luís- MA. ACopo descartável, B-Garrafa pet, C-papel e guardanapo, D - saco de estopa, E - saco plástico de supermercado cheio de restos de alimentos e $F-\operatorname{cocos}$ secos 
Os resíduos sólidos registrados, conforme figura acima são: copos descartáveis, garrafas pets, canudos, cocos d'água vazios, sacos plásticos, lenços de papel, saco de estopa, restos de lanches. Observa-se que todos os resíduos lançados foram utilizados e posteriormente abandonados nos locais. Foram ainda registradas latas enferrujadas, embalagens de biscoitos, lenços de papel, sacos de estopa, restos de lanches, tapas de garrafas plásticas, pontas de cigarros (Figura 4).

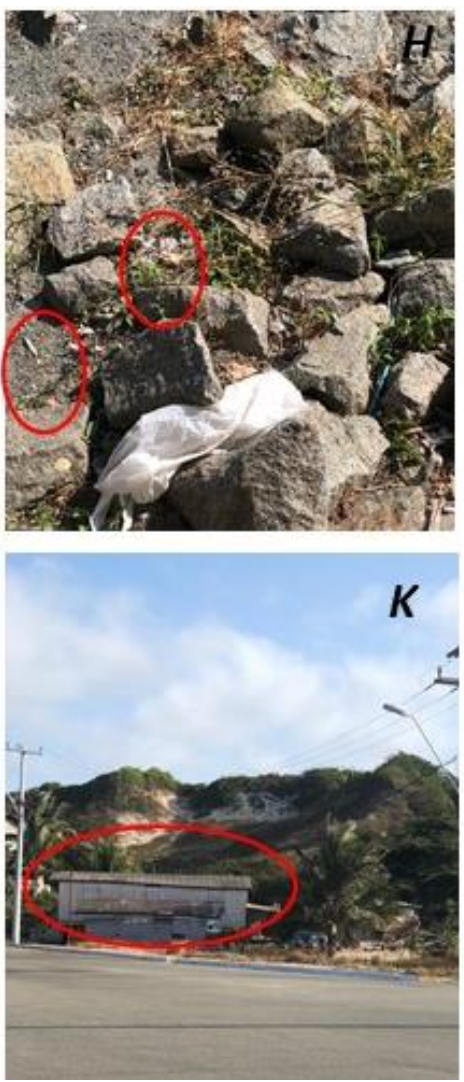
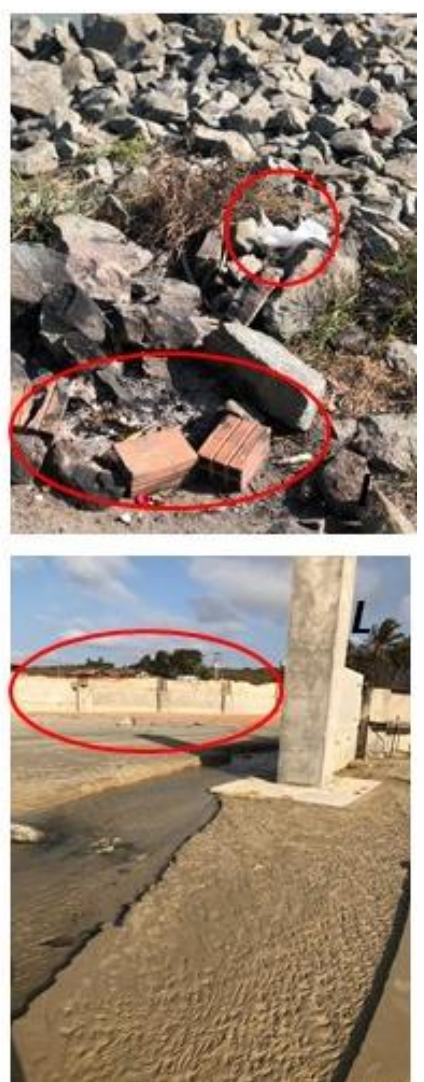

Figura 4: Impactos registrados na zona Costeira de São Luis. G- lata enferrujada, H-Pontas de cigarros e tampas de refrigerantes e cervejas, I - Tijolos e Brasa, J- Aterramento da área para construção de estabelecimento comercial, K- Residências construídas em cima de áreas aterradas, L- estruturais civis para a extensão de via de acesso.

Foi possível observar latas já em estágio avançado de corrosão, indicando já estarem abandonadas no local há um tempo longo. Muitas pontas de cigarros e tampas de refrigerantes e cervejas $(H)$, além de tijolos e restos de brasa, que sugerem a organização de uma assadeira, indicando que o local é utilizado como área de convívio social.

Portanto é possível observar que o convívio social na área, especialmente daquele desenvolvido pelo turismo, não tem sido harmônico, visto a quantidade de resíduos expostos de forma inadequada. Sobre o assunto Oliveira (2015), destaca que apesar de contribuir para o desenvolvimento local, a atividade turística está relacionada a impactos sociais, econômicos e ambientais, especialmente gerados pelo turismo de massa, 
onde, muitas vezes, "os turistas são insensíveis à cultura e às tradições locais, e pretendem apenas consumir o que a região tem a lhes oferecer". Dessa relação os ônus são visíveis nos locais turistados.

Observou-se que partes da praia foram aterradas para a construção de casas $(\mathrm{K})$ e estabelecimentos comerciais $(\mathrm{J})$. Cabe destacar que essa área aterrada faz parte de uma área de proteção da bacia do rio Pimenta, além disso nessa mesma área de influência dessa bacia hidrográfica, está sendo construído a extensão de uma via de acesso muito importante (L) para o fluxo de veículo no município de São Luís, denominada de Avenida Litorânea, cujo objetivo é desafogar o trânsito da região, além de servir como área de turismo, e outras atividades.

Foi registrado que o descarte de resíduos sólidos de estabelecimentos comerciais localizados na área, não estão sendo realizados de forma adequada (Figura 5).
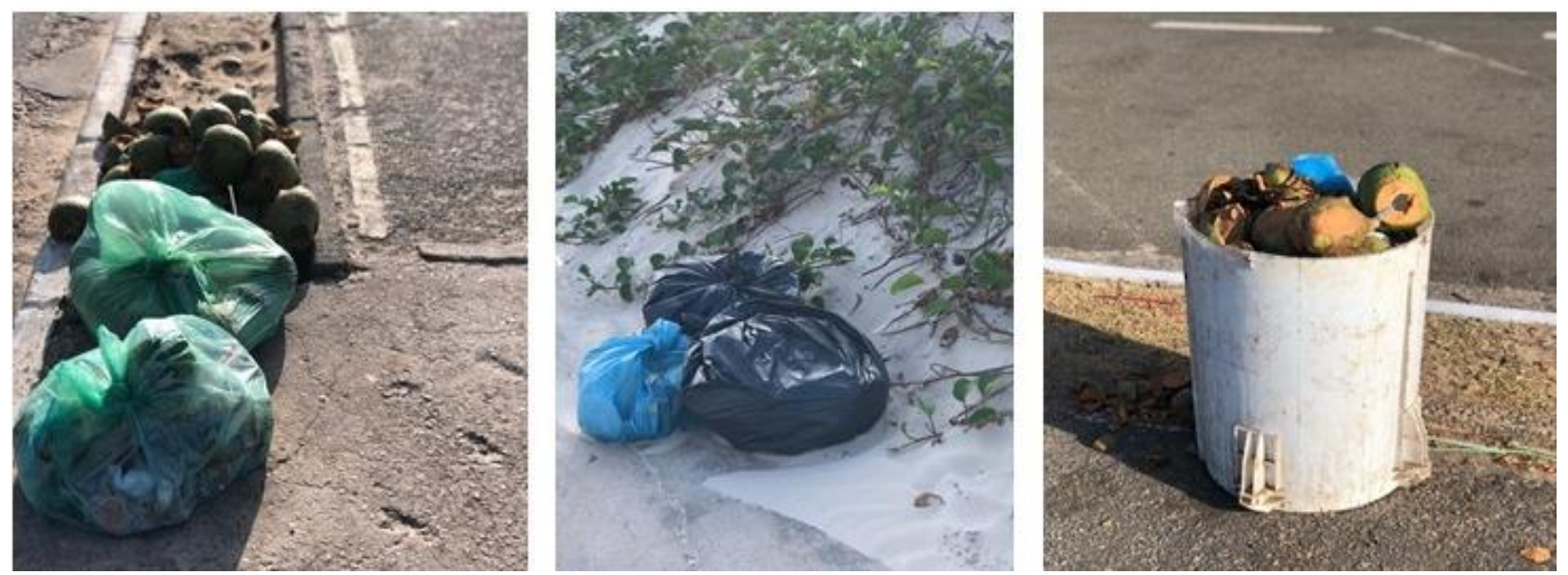

Figura 5: Descarte de resíduos sólidos realizados por estabelecimentos comerciais regulares

Percebe-se que alguns resíduos não são colocados nos sacos plásticos e ficam dispostos na parte urbanizada utilizada para o acesso de pedestres. Alguns sacos são colocados diretamente na areia, e mesmo quando existe recipientes de disposição dos resíduos, eles não possuem tampa. Além disso, foi possível perceber que não existe um horário de disposição desses resíduos, eles são colocados a qualquer hora e ficam expostos até a passagem do carro que recolhe, o que dependendo do dia da semana, pode ocorrer no turno da noite.

Em relação aos impactos naturais, foram registrados fragmentação de estruturas ocasionadas pela hidrodinâmica costeira, processos erosivos, assim como processos de corrosão de estruturas (Figuras 6 e 7, respectivamente). 

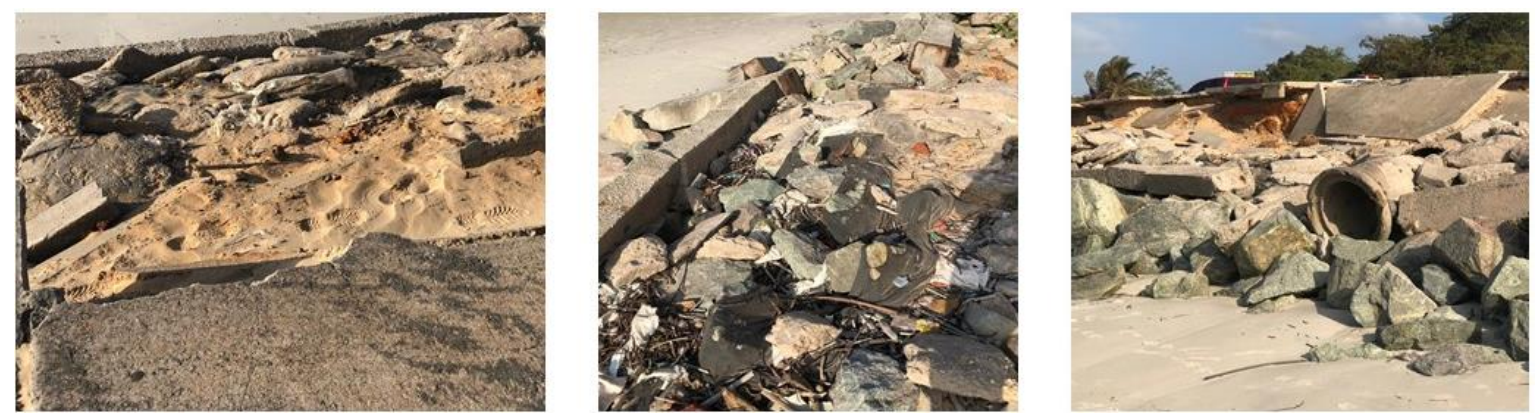

Figura 6: Registro de processos de degradação da zona costeira do município de São Luís.

Pôde-se observar que a hidrodinâmica costeira está destruindo a estrutura das vias de acesso de pedestres e ciclistas. O calçadão está em processo de rebaixamento, e em alguns pontos quase que totalmente quebrado. Em outras partes turísticas, a falta de manutenção é notória (Figura 7).
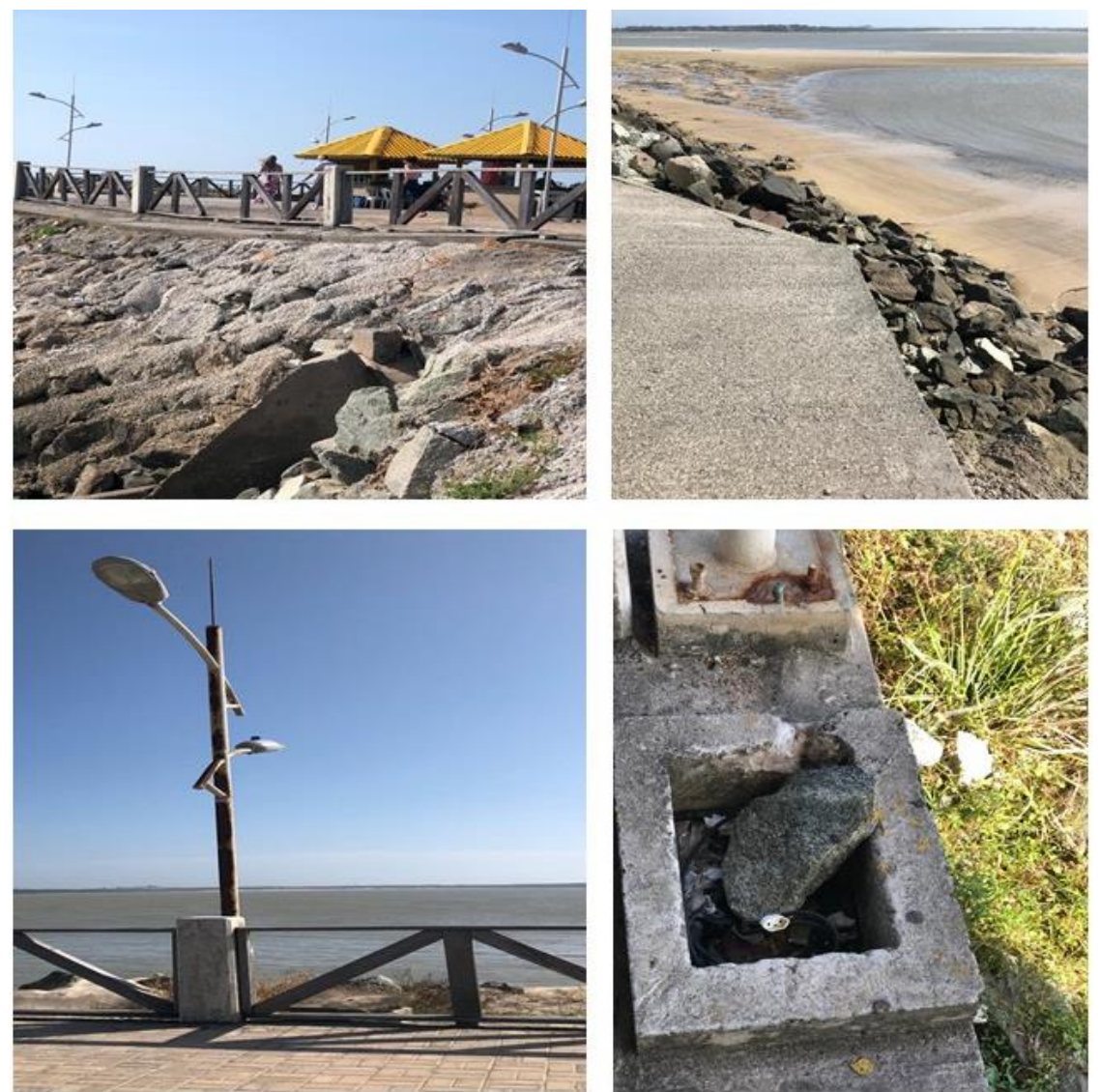

Figura 7: Estruturas degradas pela ação natural e agravadas pela falta de manutenção, no Espigão Costeiro de São Luís

$\mathrm{Na}$ Figura 7, pode ser observado o rebaixamento do calçadão do espigão costeiro da Ponta da areia em São Luís, assim como a rampa de acesso à água completamente quebrada e já sem condições de uso, as estruturas de iluminação completamente corroídas e muitas sem lâmpadas, o 
que pode deixar o local escuro durante a noite, sendo também observadas outras situações perigosas, como a falta de tampa de estruturas que contém extensões ligadas na eletricidade, estruturas pontudas e sem proteção localizadas no chão e acessíveis a crianças. O espigão costeiro da ponta d areia foi inaugurado no ano de 2014, e mesmo com apenas 5 anos de uso já encontra problemas sérios em sua estrutura.

É bom destacar que a estrutura do Espigão costeiro da Ponta da areia é um local turístico e de lazer bastante frequentado pela população da ilha e pelos turistas, e que essas situações podem expor os frequentadores a riscos.

Ao longo da extensão percorrida foram observados vários pontos de lançamentos de resíduos líquidos (esgoto in natura), o que está comprometendo a balneabilidade das praias. Em alguns pontos estão instaladas placas de sinalização (Figura 8), indicando a não balneabilidade do local, no entanto, parece que a quantidade de placas não é suficiente para indicar todos os pontos impróprios para o banho, visto que se passam muitos metros sem que apareçam outras placas.

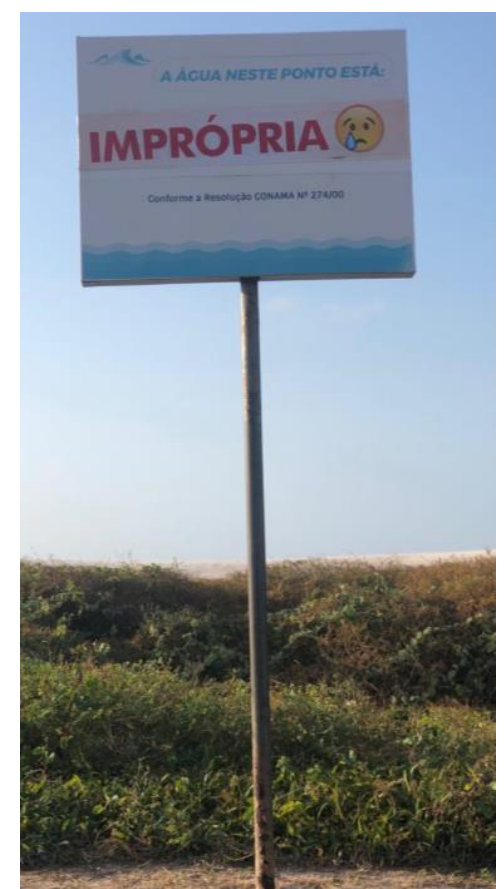

Figura 8: Placas educativas que sinalizam a não balneabilidade das praias

Além do que foi materializado pelas fotos, também foram observadas estruturas abandonadas dentro da água, como garrafas pets e uma estrutura da construção civil, muito semelhante a uma coluna de sustentação civil.

Diante dos impactos levantados, observa-se que a grande maioria são antrópicos e ocasionados pela falta de consciência da população que utiliza a área, e da falta de atuação dos gestores públicos como políticas de 
manutenção das estruturas a médio e longo prazos. Não foi observado ao longo do percurso nenhum tipo de material educativo, placas, guias ou mesmo donos de estabelecimentos comerciais que orientassem os usuários quanto aos usos de forma a manter o ambiente em condições adequadas. Por exemplo, os vendedores de coco, poderiam ter placas, cartazes que orientassem os clientes a colocarem os cocos secos, canudos, copos, guardanapos nos locais apropriados, pois quando deixados em qualquer lugar as condições de vento típicas da região costeira podem carreá-los para a água e de lá eles podem alcançar os oceanos contribuindo mais ainda para o acúmulo de lixo e trazendo consequências desastrosas para a biota. Nesse contexto a Educação Ambiental apresenta-se de estrema importância para relembrar as pessoas quanto as obrigações de cuidar do meio ambiente, através de ações simples e individuais.

Em relação ao poder público, é de extrema importância que consiga desenvolver políticas contínuas de educação das populações, além de projetos de manutenção de estruturas de espaços públicos, especialmente as localizadas em regiões de conflitos entre sistemas naturais e antrópicos, visto que o mau uso poderá acarretar impactos severos sobre a biota local.

Cabe destacar que no dia 22 de setembro de 2019 ocorreram ações mundiais de limpeza de praias e rios, e que no município de São Luís ocorreram várias dessas ações ao longo do percurso estudado nesse trabalho. As ações convergiram com o recolhimento de toneladas de lixos que estavam nas praias, e foi utilizado como um momento de conscientização sobre a importância de manter as praias limpas (Figura 9).
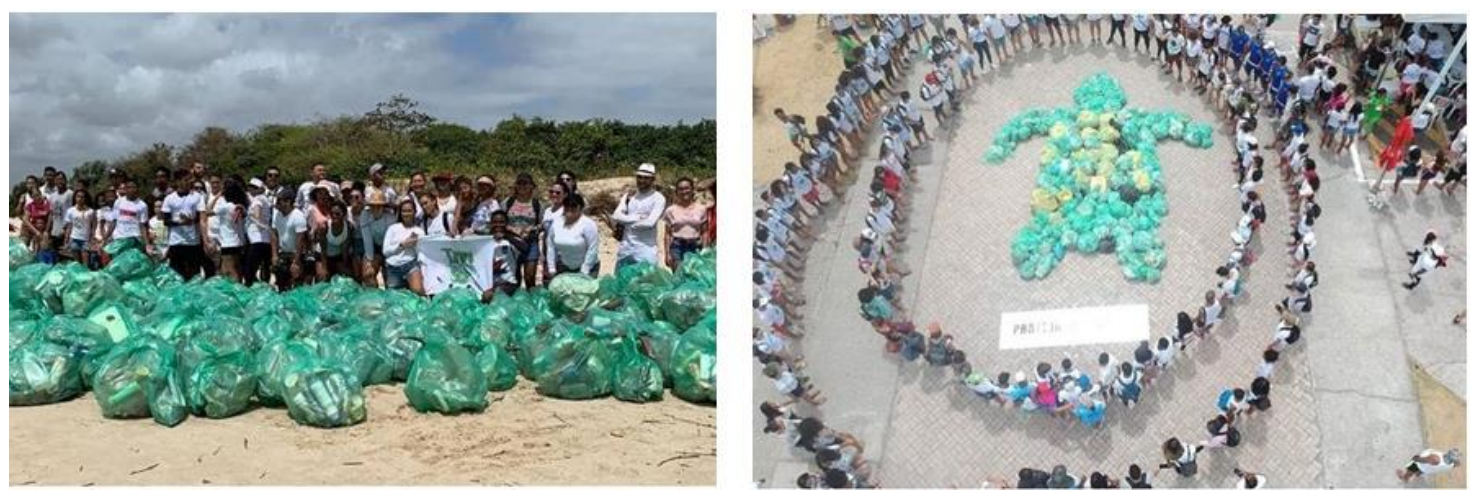

Figura 9: Ação de limpeza das praias de São Luís.

Fonte: Divulgação Prefeitura de São Luís-@Instagram.

Conforme a Figura 9, no dia da ação muito resíduo sólido que estava disposto na região foi recolhido, e no final o lixo foi empilhado como forma de chamar a atenção dos impactos que o lixo causa nos ecossistemas aquáticos e especialmente à biota a curto prazo. Cabe a reflexão de que, os ambientes naturais precisam serem mantidos limpos todos os dias, e não somente quando há ações de limpeza, assim nota-se o papel imprescindível da Educação 
Ambiental como a principal ferramenta de conscientização da população desde os primeiros anos de vida.

Cavalcante e Aloufa (2018) destacam que os ambientes costeiros são frágeis por natureza, sendo necessário estratégias premente e políticas públicas contínuas, especialmente na área de gestão ambiental e costeira, planejamento urbano, e planejamento regional, somando-se a isso a necessidade de maior frequência e rigor na fiscalização e licenciamento ambiental de atividades potencialmente poluidoras que tem colocado em risco o equilíbrio dos ecossistemas dessas áreas.

A EA é uma ação reflexiva sobre a complexidade ambiental, permitindo que o exame de valores e percepções das práticas sociais auxilia na transformação e na atitude das pessoas através de práticas educativas. Para (ANDRADE, 2019) a Educação Ambiental promove uma aprendizagem que gera processos de formação do sujeito humano. O resultado dessa aprendizagem é a conscientização ambiental, para isso, propõe a formação do sujeito ecológico. Este possui traços, valores e ânimo para lutar pelos projetos e ideais ecológicos para difundi-los na sociedade.

Dessa forma, visando melhorar o ambiente natural das praias, leva-se em conta algumas ações que poderiam ser praticadas na região costeira de São Luís, visando mitigar os impactos ambientais oriundo das práticas errôneas da população, como:

- Placas de sinalização para lixeiras, e/ou outras formas de recolher o lixo

- Placas de conscientização para que a população se sensibilize e faça sua parte.

- Aos finais de semana e feriados, dias dos quais tem maior contingente de pessoas, seria importante teatros, apresentações, das quais mostrem como é importante cuidar da natureza para esta geração e para as futuras que iram usufruir.

- Educar os donos de estabelecimentos comerciais regulares e do comercio informal sobre a importância de utilizar materiais ecológicos, como canudos, entre outros, dos quais acabam indo para o mar.

\section{Conclusões}

Os ambientes naturais localizados na zona costeira, utilizados como área de públicas de lazer, não possuem manutenções constantes nem por parte do poder público, nem dos usuários diretos dos espaços. É necessária uma avaliação permanente dos mecanismos de planejamento e gestão agregados a esses espaços. É preciso incluir nos moldes de planejamento de estratégias que possam garantir a preservação ambiental, equacionando assim o problema entre desenvolvimento econômico e conservação dos sistemas naturais.

Uma alternativa viável à implantação da conscientização constante por parte de todos os grupos usuários da zona costeira, é a Educação Ambiental, 
pois tanto comerciantes, quanto poder público, turistas, moradores, praticantes de esporte e usuários em geral precisam de informações que sejam repassadas de forma homogênea e constante a todos.

Assim propagandas em meios de comunicação, placas informativas, programas especiais de Educação Ambiental em dias de maior fluxo de turistas, panfletagens, programas que gerem alternativas sustentáveis de descarte de resíduos sólidos para os comerciantes, além de projetos de manutenção da infraestrutura e condições de uso adequadas são possibilidades que podem vir a responder de forma efetiva na manutenção de melhores condições de manutenção da zona costeira e consequentemente implicará em usos cada vez mais diversificados sobre essas áreas.

\section{Referências}

ANDRADE, M.M.,; MARQUES, M.M. A Educação Ambiental como instrumento na prevenção de riscos ambientais. Educação Ambiental em Ação, 2019.

CAVALCANTE, J.S.I. Áreas costeiras: gestão, problemáticas e percepções ambientais no município de Areia Branca, Rio Grande do Norte, Brasil. 2018. 183f. Tese (Doutorado em Desenvolvimento e Meio Ambiente) - Centro de Biociências, Universidade Federal do Rio Grande do Norte, Natal, 2018.

CORREIA, J. D. sustentabilidade dos sistemas agro-extrativos de produção da região lacustre de penalva-ma, na área de proteção ambiental da baixada maranhense. Dissertação de mestrado, 2006, pp.12-98.

GIL, A.C. Como elaborar projetos de pesquisa. São Paulo: atlas, 2007 Ventura, m. M. O estudo de caso como modalidade de pesquisa. Revista da Sociedade de Cardiologia do Estado do Rio de Janeiro, Rio de Janeiro, v.20, n.5, pp.383-386, 2007.

GRUBER, N. L. S; BARBOZA, E. G; NICOLODI, J. L. Geografia dos Sistemas Costeira e Oceanográficos: Subsídios para Gestão Integrada da Zona Costeira. Gravel. Porto Alegre, 2003. p 81-89.

RIBEIRO, K.S.; LEITE, A.D.; SILVA, J.F.; CUNHA, D.M.; CABRAL, J.S.; SANTOS, P.C. Caracterização de impactos antrópicos e naturais sobre ecossistema de manguezal: praia do caúra no município de São José de Ribamar (MA). Educação Ambiental em Ação, 2019.

OLIVEIRA, T.C.R. Uso e qualidade das praias arenosas da llha de Santa Catarina, SC, Brasil: bases para seu planejamento ambiental. 143 f. Tese (Doutorado em Geografia) - Universidade Federal de Santa Catarina, 2015.

SILVA, J.F.; LIMA, C. D. Expansão urbana na zona costeira de são luís - ma: a gestão ambiental inserida no gerenciamento costeiro. Anais do IV Congresso Brasileiro de Gestão Ambiental, 2013, pp. 1-6.

ZANELLI. J.C. Pesquisa qualitativa em estudos da gestão de pessoas. Estudos de Psicologia. 2002.

Revbea, São Paulo, V. 15, № 5: 333-344, 2020. 